\title{
Environmental Policy, Efficient Taxation and Unemployment*
}

\author{
Thomas Aronsson \\ Department of Economics, Umea University \\ S- 90187 Umea, Sweden
}

March 2003

\begin{abstract}
In this paper, I consider environmental policy as part of a mixed tax problem with a general income tax and linear commodity taxes. I assume that the wage rate is determined by bargaining between unions and firms. The results show that the change in the number of employed persons, following a change in the use of a tax instrument, affects the optimal tax structure via two channels; (i) it makes the tax revenues available for public expenditures more or less costly to collect, and (ii) it affects the aggregate demand for the good that causes the environmental damage. This means that the use of taxation to counteract the labor market imperfection is not easily separated from the environmental aspects of tax policy. As a consequence, the so called 'additivity' property characterizing the commodity tax structure in previous studies does not apply.

Keywords: Optimal taxation, external effects, unemployment

JEL classification: D62, H21, J60

*The author would like to thank Karl-Gustaf Löfgren, Tomas Sjögren and Magnus Wikström for helpful comments and suggestions. A research grant from FAS is gratefully acknowledged.
\end{abstract}




\section{Introduction}

Since the mid 1990s, the connection between environmental policy and unemployment has been explored by several studies. A basic idea here is that the structure of the labor market and the environmental damage associated with production and/or consumption are not independent of each other, meaning that their consequences for economic policy should be addressed simultaneously. One important topic in previous studies on environmental policy under unemployment is the welfare effects of green tax reforms ${ }^{1}$, whereas another is to characterize the environmental policy in the context of an optimal tax and/or expenditure structure ${ }^{2}$.

This paper follows the second line of research by considering environmental policy as part of an optimal tax and expenditure problem. Contrary to most previous studies on environmental policy under unemployment, where the authors tend to focus on proportional tax instruments, I will analyze environmental and other policies in the context of the mixed tax problem, where the set of tax instruments includes a nonlinear income tax and linear commodity taxes ${ }^{3}$. Such a framework has two main advantages. First, it provides a reasonably realistic description of the set of tax instruments that a government has at its disposal. Second, since the income tax is used for revenue collection and redistribution, it also enables me to focus more explicitly on the corrective role of commodity taxation.

The paper draws on, and tries to combine, earlier literature in primarily two fields; (i) environmental policy under optimal nonlinear taxation and

\footnotetext{
${ }^{1}$ See e.g. Schneider (1997), Bovenberg and van der Ploeg (1998), Koskela and Schöb (1999) and Koskela, Schöb and Sinn (2001).

${ }^{2}$ See e.g. Bovenberg and van der Ploeg (1996).

${ }^{3}$ Important early contributions to the mixed tax problem include Mirrlees (1976), Atkinson and Stiglitz (1976) and, in the context of public good provision, Christiansen (1981).
} 
(ii) optimal nonlinear taxation under unemployment. Previous studies on environmental policy under optimal nonlinear taxation are commonly based on the assumption that the labor market is competitive. Pirttilä and Tuomala (1997) consider environmental policy in a two-type $\operatorname{model}^{4}$, where the aggregate consumption of one of the commodities gives rise to environmental damage ${ }^{5}$. One of their main contributions is to show that the so called 'additivity' property discussed by Sandmo (1975) also applies in the context of the mixed tax problem. Additivity means here that the value of the marginal external effect enters additively in the tax formula for the commodity that gives rise to environmental damage, while it has no direct effect on the formulas for the commodity taxes on the other goods. The structure of commodity taxation in an economy with nonlinear income taxation is further analyzed by Cremer et al. (2001), who focus on the relationship between this tax structure and the underlying consumer preferences. Cremer and Gahvari (2001) extend the analysis by considering an integrated system of emission taxes (levied on firms) and commodity taxes in an economy where emissions release in the production.

Earlier studies dealing with optimal nonlinear taxation under unemployment have focused on a variety of issues. Aronsson and Sjögren (2003) consider a two-type model, where unions influence wage formation. Their contribution is to characterize the structure of income taxation, commodity taxation and public good provision under unemployment. A two-type

\footnotetext{
${ }^{4}$ See Stern (1982) and Stiglitz (1982). The study by Pirttilä and Tuomala is based on an extension of the variant of the two-type model used by Edwards et al. (1994) to analyze income taxation, commodity taxation and public good provision in an economy without any environmental damage.

${ }^{5}$ See also Aronsson and Blomquist (2003), who extend the framework of Pirttilä and Tuomala to a global economy with transboundary environmental problems and labor mobility.
} 
model where part of the individuals of the low-ability type might become unemployed is considered by Marceau and Boadway (1994) to analyze the welfare effects of minimum wages. There are also studies focusing more explicitly on the determinants of tax progression in economies with imperfect competition in the labor market; e.g. Fuest and Huber (1997) and Aronsson and Sjögren $(2002 \mathrm{a})^{6}$.

In this paper, I follow Pirttilä and Tuomala (1997) by assuming that the environmental damage is related to the aggregate consumption of a particular good, to be called a 'dirty' good. The labor market part of the model is a right-to-manage framework, where unions and firms bargain over the wage rate. The paper contributes to the literature in primarily two ways. First, it contributes by characterizing the optimal tax policy and, in particular, the corrective role of commodity taxation in an economy with environmental damage and unemployment. The analysis also makes it possible to further address the 'employment' effects influencing the policy mix that were derived by Aronsson and Sjögren (2003). A basic question is how the motives for taxation that are associated with employment effects of the policy instruments are modified in case consumption gives rise to environmental damage. Second, the paper also considers public expenditures on abatement, which means that the set of 'environmental policy instruments' is broader than in most previous studies.

The outline of the paper is as follows. Section 2 concerns the optimization problems facing consumers, firms and unions. In Section 3, I analyze the optimal tax problem and derive the main results. Section 4 summarizes the

\footnotetext{
${ }^{6}$ Fuest and Huber study the relationship between the optimal degree of tax progression and the structure of wage bargaining in an economy where the hours of work per employee are fixed. Aronsson and Sjögren relate the optimal degree of tax progression to whether employed individuals choose the hours of work themselves conditional on the wage rate, or whether a union chooses the hours of work per employee.
} 
paper.

\section{The Model}

I will consider a small open economy in which two different goods are consumed; a clean good and a dirty good, where the aggregate consumption of the dirty good gives rise to environmental damage. Since the labor market is assumed to be characterized by wage bargaining between unions and firms, I introduce production explicitly. The optimization problems of the consumers, firms and unions are described below.

\subsection{The Consumers}

There are three types of consumers; employed workers, unemployed workers and firm-owners ${ }^{7}$. To simplify the analysis, the only type of income facing workers is labor income or unemployment benefits, depending on the status of employment, whereas the firm-owners only receive profit income. The consumers have the same preferences described by the utility function $U\left(c_{1}, c_{2}, z, x\right)$, where $c_{1}$ is the clean private consumption good, $c_{2}$ the dirty private consumption good, $z$ leisure and $x$ environmental damage (to be defined below). I assume that $U(\cdot)$ is increasing in $c_{1}, c_{2}$ and $z$, decreasing in $x$ and strictly quasiconcave. Leisure is, in turn, defined as $z=H-l$, where $H$ is a time endowment and $l$ the hours of work. The producer prices are denoted by $Q_{j}$ for $j=1,2$, and the small open economy framework is

\footnotetext{
${ }^{7}$ To simplify the labor market part of the model (see below), I assume decreasing returns to scale, where labor is the only variable production factor. The firm-owners (or owners of any fixed production factor) receive the profit as income. Instead of introducing the firm-owners, an alternative would be to assume that the profit is distributed among the employed and unemployed. It is not important for the qualitative results which option is chosen, and the choice to introduce the firm-owners is made for analytical convenience.
} 
interpreted to mean that the producer prices are fixed. The consumer prices are given by $q_{j}=Q_{j}+t_{j}$ for $j=1,2$, where $t_{j}$ is a commodity tax.

There are $m$ workers in the labor force, among which $n$ are employed and $m-n$ unemployed. Each employed worker ${ }^{8}$ faces the gross income $w l$, where $w$ is the wage rate, and chooses $c_{1}, c_{2}$ and $l$ to maximize the utility subject to the budget constraint. Following Christiansen (1984), it will be convenient to start by solving the utility maximization problem conditional on the hours of work. This decision problem can be written as

$$
\max _{c_{1}, c_{2}} U\left(c_{1}, c_{2}, z, x\right)
$$

subject to

$$
B^{e}=\sum_{j=1}^{2} q_{j} c_{j}
$$

in which $B^{e}$ is a fixed budget to be allocated between the commodities, and the superindex " $e$ " refers to 'employed'. The consumer treats the environmental damage as exogenous during optimization. By solving the conditional utility maximization problem, we obtain the conditional demand functions, $c_{j}^{e}=c_{j}\left(\mathbf{q}, B^{e}, z, x\right)$ for $j=1,2$, where $\mathbf{q}$ is the consumer price vector. The conditional indirect utility function becomes $v^{e}=v\left(\mathbf{q}, B^{e}, z, x\right)$.

The hours of work can then be derived by maximizing the conditional indirect utility function with respect to $l$ subject to the budget constraint,

\footnotetext{
${ }^{8}$ To simplify the analysis, I have chosen to follow Fuest and Huber (1997) and Aronsson and Sjögren (2002a, 2002b) by disregarding the possibility that employed individuals may differ in ability. As I will explain below, this means neglecting motives for tax progression that also apply under competition in the labor market. This simplification enables me to focus on the corrective role of taxation, although the mechanisms via which the corrective policy works would remain valid also in a more general framework with more than one employed ability-type.
} 
$B^{e}=w l-T(w l)$, where $T(\cdot)$ is the income tax function. The first order condition is given by

$$
\frac{\partial v^{e}}{\partial B^{e}} w\left(1-T_{y}\right)-\frac{\partial v^{e}}{\partial z}=0
$$

in which $y=w l$ and $T_{y}=\partial T / \partial y$.

Each unemployed worker receives a fixed tax-free benefit, $b$, and the budget constraint is written $B^{u}=b=\sum_{j=1}^{2} q_{j} c_{j}$, where the superindex " $u$ " refers to 'unemployed'. By analogy to the analysis carried out above, the conditional demand functions become $c_{j}^{u}=c_{j}\left(\mathbf{q}, B^{u}, H, x\right)$ for $j=1,2$, and the conditional indirect utility function is written $v^{u}=v\left(\mathbf{q}, B^{u}, H, x\right)$.

I assume that the firm-owners do not work, meaning that their only source of income is profit. Since the number of firm-owners is not important, it will be normalized to one. The budget constraint facing the firm-owner is given by $B^{p}=\pi(1-s)$, where $\pi$ is the profit income and $s$ the profit income tax rate, while the superindex " $p$ " is used to denote 'firm-owner'. The conditional demand functions and the conditional indirect utility function are given by $c_{j}^{p}=c_{j}\left(\mathbf{q}, B^{p}, H, x\right)$ for $j=1,2$, and $v^{p}=v\left(\mathbf{q}, B^{p}, H, x\right)$, respectively.

Note that, by using the budget constraints, $B^{i}=\sum_{j} q_{j} c_{j}^{i}$ for $i=e, u, p$, together with $q_{j}=Q_{j}+t_{j}$, one can show that the conditional demand functions obey the following 'adding-up' conditions;

$$
\begin{aligned}
\sum_{j=1}^{2} Q_{j} \frac{\partial c_{j}^{i}}{\partial B^{i}} & =1-\sum_{j=1}^{2} t_{j} \frac{\partial c_{j}^{i}}{\partial B^{i}} \text { for } i=e, u, p \\
-\sum_{j=1}^{2} Q_{j} \frac{\partial c_{j}^{e}}{\partial z} & =\sum_{j=1}^{2} t_{j} \frac{\partial c_{j}^{e}}{\partial z}
\end{aligned}
$$

which are useful below.

Before proceeding, one needs to specify how the environmental damage is determined. I assume that the environmental damage is given by 


$$
x=\rho\left(C_{2}, \alpha\right)
$$

where $C_{2}=n c_{2}^{e}+(m-n) c_{2}^{u}+c_{2}^{p}$ is the aggregate demand for the dirty good, and $\alpha$ the public resources spent on abatement. The function $\rho(\cdot)$ is such that $\partial \rho(\cdot) / \partial C_{2}>0$ and $\partial \rho(\cdot) / \partial \alpha<0$.

\subsection{The Firms}

To make the production part of the model as simple as possible, I assume that the clean good is produced domestically, while the dirty good is imported. Export revenues, from selling the clean good abroad, are used to finance the import of the dirty good. The small open economy assumption means that the producer prices are determined on the world market. I also assume that the domestic goods market is competitive and consists of identical firms. Since the number of firms is not important, it will be normalized to one. Labor is the only variable production factor. The objective function of the firm is given by

$$
\pi=Q_{1} f(L)-w L
$$

where $L$ is the total hours of work in the economy and measured as the hours of work per employee, $l$, times the number of employed persons, $n$. The function $f(\cdot)$ is increasing in its argument and strictly concave. The first order condition defines a labor demand function, $L=L(w)$, where $\partial L(w) / \partial w<0$ and the fixed producer price has been suppressed for notational convenience.

\subsection{Wage Formation}

The wage formation part of the model is based on Aronsson and Sjögren (2002b). I assume that wage formation is decentralized in the sense that 
the unions treat the policy instruments of the government as exogenous ${ }^{9}$. Given this characteristic, the number of unions is not important and will be normalized to one. The union acts in accordance with the expected utility framework. If we define the labor demand measured in terms of the number of employed persons as $n=\hat{n}(w, l)=L(w) / l$, the objective function of the union can be written as

$$
V=\frac{\hat{n}(w, l)}{m} v^{e}+\left(1-\frac{\hat{n}(w, l)}{m}\right) v^{u}
$$

where $v^{e}=v\left(\mathbf{q}, B^{e}, z, x\right)$ and $v^{u}=v\left(\mathbf{q}, B^{u}, H, x\right)$ as defined above.

The wage rate is determined by bargaining between the union and the firm in the context of the 'right-to-manage' framework ${ }^{10}$. If no contract is signed, the union members become unemployed and obtain the fall-back utility, $v^{u}$, which is exogenous to the union by the assumption of local wage formation above, whereas the fall-back profit of the firm is zero. Defining $\Phi=V-v^{u}$ to be the union's rent from bargaining, the outcome of the bargain will be the wage rate that maximizes the Nash product

$$
\Omega=\Phi^{a} \pi^{1-a}
$$

subject to the private budget constraint, $B^{e}=w l-T(w l)$, where $a$ is the relative bargaining power of the union. By assuming that the wage rate is decided upon conditional on $l$, the first order condition can be written ${ }^{11}$

\footnotetext{
${ }^{9}$ Real world wage formation systems differ substantially with respect to centralization, where the U.S. is an example of relatively decentralized wage formation, whereas certain European countries are characterized by more centralized wage formation. The optimal tax problem set out below does not necessarily require local wage formation per se; the important assumption is that the unions are small relative to the government, which makes it possible to formulate the optimal tax problem in the traditional way with the government acting leader and the private sector (including the unions) follower.

${ }^{10}$ See Oswald (1985).

${ }^{11}$ Another possibility would be to assume that the union behaves as a Stackelberg
} 


$$
\Omega_{w}=\left[a \pi V_{w}+(1-a) \Phi \pi_{w}\right] \Phi^{\alpha-1} \pi^{-\alpha}=0
$$

where $V_{w}=[(\partial \hat{n} / \partial w) / m]\left(v^{e}-v^{u}\right)+(n / m)\left[\partial v^{e} / \partial B^{e}\right] l\left(1-T_{y}\right)$ and $\pi_{w}=-L$. The second order sufficient condition, $\Omega_{w w}<0$, is assumed to be fulfilled. Finally, if we use $\left[\partial v^{e} / \partial B^{e}\right]\left(1-T_{y}\right)=\left[\partial v^{e} / \partial z\right] / w$ from equation (3), and substitute into equation (8) to eliminate $\left[\partial v^{e} / \partial B^{e}\right]\left(1-T_{y}\right)$ in the expression for $V_{w}$, one obtains a modified first order condition, $\tilde{\Omega}_{w}=0$, which implicitly defines a wage equation of the form;

$$
w=w\left(\mathbf{q}, B^{e}, l, B^{u}, x\right)
$$

where the parameter $a$ has been suppressed. Equation (9) gives the equilibrium wage rate as a function of some of the policy instruments facing the government (see below). To assure that this wage equation is well defined, and in line with the assumption that $\Omega_{w w}<0$ above, I assume that $\tilde{\Omega}_{w w}<0$. Equation (9) then implies $\partial w / \partial l>0, \partial w / \partial B^{u}>0$, while the other partial derivatives can be either positive or negative.

The labor market is in equilibrium, when equations (3) and (9) are satisfied simultaneously. The wage equation and the labor demand function together define the following reduced form equation for the number of employed persons;

$$
n=\hat{n}\left(w\left(\mathbf{q}, B^{e}, l, B^{u}, x\right), l\right)=n\left(\mathbf{q}, B^{e}, l, B^{u}, x\right)
$$

leader in the sense of recognizing that the hours of work chosen by its members respond to a change in the wage rate, or that the union and the firm bargain over the hours of work. Such extensions will not be considered here. The reader is referred to Aronsson and Sjögren (2002a) for a study of tax progression in case a monopoly union chooses the hours of work. 


\section{The Optimal Tax and Expenditure Problem}

The set of policy instruments facing the government consists of the parameters of the labor income tax function, $T(\cdot)$, the income tax rate of the firm-owner, $s$, the commodity taxes, $t_{1}$ and $t_{2}$, the unemployment benefit, $b$, and the expenditures on abatement, $\alpha$. Since $T(\cdot)$ is a general income tax function, it can be used to induce any desired combination of $B^{e}$ and $l$, meaning that the parameters of $T(\cdot)$ and $\left(B^{e}, l\right)$ constitute two equivalent sets of policy instruments. For purposes of convenience, I will use $B^{e}$ and $l$ instead of the parameters of the tax function as decision variables of the government. In a similar way, since the government controls the size of profits, via the determinants of $L$ and $w$, as well as chooses the profit income tax rate, it effectively controls the size of $B^{p}$. I will, therefore, use $B^{p}$ instead of $s$ as a decision variable. This means that the optimization problem facing the government will be formulated such that $B^{e}, l, B^{u}, B^{p}, t_{1}, t_{2}$ and $\alpha$ are decision variables. The solution to the government's optimization problem implicitly defines the tax and expenditure policies that, if introduced in the decentralized economy, make the private agents choose this resource allocation themselves.

I will formulate the policy problem such that the government wants to find the pareto efficient tax and expenditure structure. To be more specific, I assume that the government chooses its policy instruments by maximizing the utility of the unemployed subject to minimum utility restrictions for the employed and the firm-owner, respectively;

$$
\begin{gathered}
v^{e}=v\left(\mathbf{q}, B^{e}, z, x\right) \geq \bar{v}^{e} \\
v^{p}=v\left(\mathbf{q}, B^{p}, H, x\right) \geq \bar{v}^{p}
\end{gathered}
$$


To be able to implement the public policy, the redistribution between the employed and the unemployed must not be such that unemployment becomes preferable to employment. I will, therefore, add the constraint;

$$
v^{e}=v\left(\mathbf{q}, B^{e}, z, x\right) \geq v^{u}=v\left(\mathbf{q}, B^{u}, H, x\right)
$$

In addition to equations (11), (12) and (13), the government also obeys its budget constraint. The budget constraint of the government takes the form

$$
n T+s \pi+\sum_{j=1}^{2} t_{j}\left[n c_{j}^{e}+(m-n) c_{j}^{u}+c_{j}^{p}\right]-(m-n) b-\alpha=0
$$

Since the optimization problem to be formulated below neither uses $T$ nor $s$ as direct decision variables, it is convenient to write the budget constraint in a way such that these variables are eliminated. By using the private budget constraints, the objective function of the firm, the identity $q_{j}=Q_{j}+t_{j}$ and equation (14), the government's budget constraint can be rewritten as

$$
Q_{1} f(n l)-\sum_{j=1}^{2} Q_{j}\left[n c_{j}^{e}+(m-n) c_{j}^{u}+c_{j}^{p}\right]-\alpha=0
$$

where $c_{j}^{e}=c_{j}\left(\mathbf{q}, B^{e}, z, x\right), c_{j}^{u}=c_{j}\left(\mathbf{q}, B^{u}, H, x\right), c_{j}^{p}=c_{j}\left(\mathbf{q}, B^{p}, H, x\right)$ and $n=n\left(\mathbf{q}, B^{e}, l, B^{u}, x\right)$.

The government maximizes $v^{u}$ subject to equations (11), (12), (13) and (15), as well as subject to the additional restriction that $x=\rho\left(C_{2}, \alpha\right)$, meaning that $x$ is treated as an additional decision variable. This formulation is analogous to Pirttilä and Tuomala (1997) and is convenient is the sense of allowing us to define a shadow price for environmental damage. The Lagrangean becomes 


$$
\begin{aligned}
\mathfrak{L}= & v^{u}+\delta\left[v^{e}-\bar{v}^{e}\right]+\zeta\left[v^{p}-\bar{v}^{p}\right]+\lambda\left[v^{e}-v^{u}\right] \\
& +\gamma\left[Q_{1} f(n l)-\sum_{j=1}^{2} Q_{j}\left(n c_{j}^{e}+(m-n) c_{j}^{u}+c_{j}^{p}\right)-\alpha\right] \\
& +\mu\left[x-\rho\left(C_{2}, \alpha\right)\right]
\end{aligned}
$$

By using $q_{j}=Q_{j}+t_{j}$ together with the private budget constraints and the necessary condition for the firm, the first order conditions for $l, B^{e}, B^{u}, B^{p}$, $t_{1}, t_{2}, \alpha$ and $x$ can be written as

$$
\begin{gathered}
-(\delta+\lambda) \frac{\partial v^{e}}{\partial z}+\gamma\left[w n+\Gamma \frac{\partial n}{\partial l}+n \sum_{j} Q_{j} \frac{\partial c_{j}^{e}}{\partial z}\right]-\mu \frac{\partial \rho}{\partial C_{2}} \frac{\partial C_{2}}{\partial l}=0 \\
(\delta+\lambda) \frac{\partial v^{e}}{\partial B^{e}}+\gamma\left[\Gamma \frac{\partial n}{\partial B^{e}}-n \sum_{j} Q_{j} \frac{\partial c_{j}^{e}}{\partial B^{e}}\right]-\mu \frac{\partial \rho}{\partial C_{2}} \frac{\partial C_{2}}{\partial B^{e}}=0 \\
(1-\lambda) \frac{\partial v^{u}}{\partial B^{u}}+\gamma\left[\Gamma \frac{\partial n}{\partial B^{u}}-(m-n) \sum_{j} Q_{j} \frac{\partial c_{j}^{u}}{\partial B^{u}}\right]-\mu \frac{\partial \rho}{\partial C_{2}} \frac{\partial C_{2}}{\partial B^{u}}=0 \\
\zeta \frac{\partial v^{p}}{\partial B^{p}}-\gamma \sum_{j} Q_{j} \frac{\partial c_{j}^{p}}{\partial B^{p}}-\mu \frac{\partial \rho}{\partial C_{2}} \frac{\partial C_{2}}{\partial B^{p}}=0 \\
(1-\lambda) \frac{\partial v^{u}}{\partial q_{k}}+(\delta+\lambda) \frac{\partial v^{e}}{\partial q_{k}}+\zeta \frac{\partial v^{p}}{\partial q_{k}}+\gamma\left[\Gamma \frac{\partial n}{\partial q_{k}}+\sum_{j} Q_{j}\left\{n \frac{\partial c_{j}^{e}}{\partial q_{k}}\right.\right. \\
\left.\left.+(m-n) \frac{\partial c_{j}^{u}}{\partial q_{k}}+\frac{\partial c_{j}^{p}}{\partial q_{k}}\right\}\right]-\mu \frac{\partial \rho}{\partial C_{2}} \frac{\partial C_{2}}{\partial q_{k}}=0 \text { for } k=1,2 \\
-\gamma-\mu \frac{\partial \rho}{\partial \alpha}=0
\end{gathered}
$$




$$
\begin{gathered}
(1-\lambda) \frac{\partial v^{u}}{\partial x}+(\delta+\lambda) \frac{\partial v^{e}}{\partial x}+\zeta \frac{\partial v^{p}}{\partial x}+\gamma\left[\Gamma \frac{\partial n}{\partial x}+\sum_{j} Q_{j}\left\{n \frac{\partial c_{j}^{e}}{\partial x}\right.\right. \\
\left.\left.+(m-n) \frac{\partial c_{j}^{u}}{\partial x}+\frac{\partial c_{j}^{p}}{\partial x}\right\}\right]+\mu-\mu \frac{\partial \rho}{\partial C_{2}} \frac{\partial C_{2}}{\partial x}=0
\end{gathered}
$$

where $\Gamma=\left(T+B^{u}\right)+\sum_{j} t_{j}\left(c_{j}^{e}-c_{j}^{u}\right)$ is the change in tax revenues net of transfer payments, if one additional person becomes employed.

\subsection{The Shadow Price of Environmental Damage}

To be able to infer the optimal tax structure from equations (17)-(23), it is convenient to start by deriving an expression for the shadow price of environmental damage over the shadow price of the government's budget constraint, $\mu / \gamma$. One can interpret $\mu / \gamma$ as measuring the marginal social value in real terms of reduced environmental damage. As such, it will constitute an important part of the tax formulas to be derived below. To begin with, define the marginal willingness to pay by each agent-type for reduced environmental damage; $M W P_{x, B}^{i}=-\left[\partial v^{i} / \partial x\right] /\left[\partial v^{i} / \partial B^{i}\right]$ for $i=e, u, p$. I will also use the Slutsky-type relationships ${ }^{12}$

$$
\begin{gathered}
\frac{\partial c_{j}^{i}}{\partial x}=\frac{\partial \tilde{c}_{j}^{i}}{\partial x}-\frac{\partial c_{j}^{i}}{\partial B^{i}} M W P_{x, B}^{i} \\
\sum_{j} Q_{j} \frac{\partial \tilde{c}_{j}^{i}}{\partial x}=M W P_{x, B}^{i}-\sum_{j} t_{j} \frac{\partial \tilde{c}_{j}^{i}}{\partial x}
\end{gathered}
$$

where $\tilde{c}_{j}^{i}$ is the compensated demand for good $j$ by agent type $i$. Note that $\partial v^{i} / \partial x$ in equation (23) may be written $-M W P_{x, B}^{i}\left(\partial v^{i} / \partial B^{i}\right)$, where

\footnotetext{
${ }^{12}$ To derive equation (24), differentiate

$$
\tilde{c}_{j}\left(\mathbf{q}, U^{i}, z, x\right)=c_{j}\left(\mathbf{q}, \xi\left(\mathbf{q}, U^{i}, z, x\right), z, x\right)
$$
}

with respect to $x$, where $\xi(\cdot)$ is the expenditure function. 
$\partial v^{i} / \partial B^{i}$ for $i=e, u, p$ can be defined from equations (18), (19) and (20), respectively. Then, by using equations (24) and (25), we can derive;

Proposition 1 Within the given framework, pareto efficient taxation means that the shadow price of environmental damage over the shadow price of the government's budget constraint takes the form

$$
\begin{aligned}
\frac{\mu}{\gamma}= & \frac{1}{1-\nu}\left[n M W P_{x, B}^{e}+(m-n) M W P_{x, B}^{u}+M W P_{x, B}^{p}\right. \\
& -\Gamma\left(\frac{\partial n}{\partial x}+M W P_{x, B}^{e} \frac{\partial n}{\partial B^{e}}+M W P_{x, B}^{u} \frac{\partial n}{\partial B^{u}}\right) \\
& \left.-\sum_{j} t_{j}\left(n \frac{\partial \tilde{c}_{j}^{e}}{\partial x}+(m-n) \frac{\partial \tilde{c}_{j}^{u}}{\partial x}+\frac{\partial \tilde{c}_{j}^{p}}{\partial x}\right)\right]
\end{aligned}
$$

where

$$
\begin{aligned}
\nu= & \frac{\partial \rho}{\partial C_{2}}\left[\left\{\frac{\partial n}{\partial x}+M W P_{x, B}^{e} \frac{\partial n}{\partial B^{e}}+M W P_{x, B}^{u} \frac{\partial n}{\partial B^{u}}\right\}\left(c_{2}^{e}-c_{2}^{u}\right)\right. \\
& \left.+n \frac{\partial \tilde{c}_{2}^{e}}{\partial x}+(m-n) \frac{\partial \tilde{c}_{2}^{u}}{\partial x}+\frac{\partial \tilde{c}_{2}^{p}}{\partial x}\right]
\end{aligned}
$$

The first three terms within the bracket in the first row of equation (26) together represent the sum of the marginal willingness to pay for reduced environmental damage. To be able to interpret the second row, recall that $\Gamma=\left(T+B^{u}\right)+\sum_{j} t_{j}\left(c_{j}^{e}-c_{j}^{u}\right)$ measures the change in tax revenues net of transfer payments if one additional person becomes employed. Since higher employment means higher income tax revenues net of transfer payments, i.e. $T+B^{u}>0$, and because the state of employment typically implies greater possibilities for consumption than the state of unemployment, one would normally expect $\Gamma>0$. In this situation, $\partial n / \partial x<0(>0)$ means a higher (lower) value of $\mu / \gamma$, since reducing $x$ gives rise to an additional gain (cost) in terms of higher (lower) employment. As such, the employment effect will make the tax revenues become less (more) costly to collect. 
The remaining two terms in the second row are associated with the effects of $B^{e}$ and $B^{u}$, respectively, on the number of employed persons. Their appearances in equation (26) are due to the fact that it is generally possible to reach a given utility level with different combinations of private income and environmental quality. If consideration for employment imposes restrictions on the size of private income, meaning that the optimal private income takes a lower value than it would otherwise have done, the government can to some extent compensate the consumers via less environmental damage. This is most easily exemplified by the effect of $B^{u}$. Since $\partial n / \partial B^{u}<0$, concern for employment tends to reduce the size of the unemployment benefit (see equation (19)). The latter means, in turn, that the government has an incentive to 'compensate' the unemployed by slightly increasing $\mu / \gamma$. The influence of $B^{e}$ in the second row can be given a similar interpretation.

The third row of equation (26) represents the tax base effects associated with the environmental damage, which are measured conditional on the number of employed persons. The intuition is that, if $\partial \tilde{c}_{j}^{i} / \partial x>0(<0)$ for $i=e, u, p$, then a reduction of $x$ gives rise to an extra cost (gain) in terms of a smaller (larger) tax base for commodity $j$. These effects have been analyzed by Pirttilä and Tuomala (1997) and will not be further discussed here.

The environmental feedback term in equation (26), denoted by $\nu$, arises because the environmental damage affects the aggregate demand for the dirty good. The second row of the formula for $\nu$ is equivalent to the feedback effect derived by Pirttilä and Tuomala under the assumption of a competitive labor market, whereas the first row reflects that (in case of union wage setting) changes in the number of employed persons generally influence the aggregate demand for the dirty good. This means that, in addition to the employment effects associated with the government's budget constraint 
discussed above, there is an employment effect related to the difference between $c_{2}^{e}$ and $c_{2}^{u}$. If this difference is positive (negative), a decrease in the employment reduces (increases) the aggregate demand for the dirty good. Therefore, if we were to assume that $\Gamma>0$ and $c_{2}^{e}>c_{2}^{u}$ (both of which may seem reasonable provided that the employed have higher income than the unemployed), the employment effects in the numerator and denominator of equation (26) affect $\mu / \gamma$ in opposite directions.

The following result provides a complement to Proposition 1;

Proposition 2 Within the given framework, $\mu / \gamma>0$ at the optimum.

Proposition 2 follows from equation (22), because $\partial \rho / \partial \alpha<0$. This is the most important consequence of allowing abatement to be part of the set of policy instruments. Therefore, as long as the marginal cost in real terms of reducing the environmental damage by abatement is positive, the marginal benefit of doing so must be positive as well at the optimum. In the absence of abatement, on the other hand, $\mu / \gamma$ can be either positive or negative. The reason is that the tax structure reflects a mixture of institutional characteristics, and not just characteristics associated with the environment, which will be discussed further below.

\subsection{The Tax Structure}

We are now in the position to discuss tax policy more explicitly. Let me begin by analyzing the effective marginal tax rate facing the employed. The total tax paid by an employed consumer is given by

$$
\tau=T(w l)+\sum_{j} t_{j} c_{j}^{e}\left(\mathbf{q}, B^{e}, z, x\right)
$$

By using $z=H-l, B^{e}=w l-T(w l)$ and $l=y / w$, and then differentiating equation (27) with respect to $y$, we obtain an expression for the effective 
marginal tax rate; $\tau_{y}=T_{y}+\sum_{j} t_{j}\left[\left(\partial c_{j}^{e} / \partial B^{e}\right)\left(1-T_{y}\right)-(1 / w)\left(\partial c_{j}^{e} / \partial z\right)\right]$. I will characterize the effective marginal tax rate in terms of employment effects of the policy instruments as well as in terms of $\mu / \gamma$. Consider the following result;

Proposition 3 Within the given framework, pareto efficient taxation means that the effective marginal tax rate facing each employed individual can be written as

$$
\begin{aligned}
\tau_{y}= & \frac{1}{w n}\left[-\Gamma+\frac{\mu}{\gamma} \frac{\partial \rho}{\partial C_{2}}\left(c_{2}^{e}-c_{2}^{u}\right)\right]\left[\frac{\partial n}{\partial l}+\left(\frac{\partial v^{e}}{\partial z} / \frac{\partial v^{e}}{\partial B^{e}}\right) \frac{\partial n}{\partial B^{e}}\right] \\
& -\frac{\mu}{\gamma} \frac{\partial \rho}{\partial C_{2}} \frac{\partial \tilde{c}_{2}^{e}}{\partial z}
\end{aligned}
$$

Proof: see the Appendix.

Note first that, in the model set out here, the effective marginal tax rate only reflects a corrective role of taxation, which is associated with imperfect competition in the labor market and environmental damage, respectively. This is seen by observing that, if the labor market was competitive $(n=$ $m$ ), and in the absence of environmental damage $(\mu / \gamma=0)$, the effective marginal tax rate would equal zero.

In Proposition 3, the changes in the number of employed persons from increases in the hours of work and the private income, respectively, play a key role. I show in the Appendix that if private income and leisure are complementary in the sense that $\partial^{2} v^{e} / \partial z \partial B^{e} \geq 0$, then

$$
\frac{\partial n}{\partial l}+\left(\frac{\partial v^{e}}{\partial z} / \frac{\partial v^{e}}{\partial B^{e}}\right) \frac{\partial n}{\partial B^{e}}<0
$$

The interpretation of equation (29) is straight forward. First, notice that equations (9) and (10) imply $\partial n / \partial l=\partial \hat{n} / \partial l+(\partial \hat{n} / \partial w)(\partial w / \partial l)<0$. This means that an increase in the hours of work decreases the number of employed persons via two different channels; (i) a direct effect (since the hours 
of work and the number of employed persons are substitutes in terms of the production function), and (ii) by changing the wage rate. Both these mechanisms imply that the number of employed persons decreases, if the hours of work per employee increase. Given that the first part of equation (29) is signed, the condition that $\partial^{2} v^{e} / \partial z \partial B^{e} \geq 0$ is sufficient to ensure that the two terms sum to a negative number. The latter is a consequence of union wage setting: if $\partial^{2} v^{e} / \partial z \partial B^{e} \geq 0$, equation (3) means that $\partial\left[\left(\partial v^{e} / \partial B^{e}\right) w\left(1-T_{y}\right)\right] / \partial B^{e} \geq 0$, which induces the union to try to increase the wage rate.

Although the terms in the first row of equation (28) have ambiguous signs in general, it is convenient to base the interpretation on the discussion above. If equation (29) is negative and $\Gamma>0$, then the first part of the first row of equation (28),

$$
-\Gamma\left[\frac{\partial n}{\partial l}+\left(\frac{\partial v^{e}}{\partial z} / \frac{\partial v^{e}}{\partial B^{e}}\right) \frac{\partial n}{\partial B^{e}}\right]
$$

is positive and contributes to increase the effective marginal tax rate. This means that, in the absence of environmental damage, imperfect competition in the labor market (caused by union wage formation) leads to a positive effective marginal tax rate. A similar result has been derived by Aronsson and Sjögren (2002b), although commodity taxes were absent in their model. The intuition is that by slightly increasing the effective marginal tax rate above zero, one can discourage the labor supply among the employed, which increases the number of employed persons.

On the other hand, the second part of the first row of equation (28),

$$
\frac{\mu}{\gamma} \frac{\partial \rho}{\partial C_{2}}\left(c_{2}^{e}-c_{2}^{u}\right)\left[\frac{\partial n}{\partial l}+\left(\frac{\partial v^{e}}{\partial z} / \frac{\partial v^{e}}{\partial B^{e}}\right) \frac{\partial n}{\partial B^{e}}\right]
$$

is negative if $c_{2}^{e}>c_{2}^{u}$. This is so because, by increasing the number of employed persons, the aggregate demand for the dirty good increases. As 
such, the latter provides an incentive to reduce the effective marginal tax rate slightly below zero, which stimulates the labor supply among the employed and, as a consequence, reduces the number of employed persons. Therefore, the two employment effects in the first row of equation (28) are likely to affect the effective marginal tax rate in opposite directions. Whether or not it is desirable to use the tax system in order to try to increase the employment will then remain an open question. At the same time, we cannot rule out the possibility that $c_{2}^{e} \leq c_{2}^{u}$, in which case the first row contributes to a positive effective marginal tax rate under the conditions presented above.

The second row of equation (28) constitutes an environmental motive for taxation that is not associated with the employment. If the dirty good is complementary with (substitutable for) leisure in the sense that $\partial \tilde{c}_{2}^{e} / \partial z>0$ $(<0)$, there is an incentive to decrease the demand for the dirty good by increasing (decreasing) the labor supply. This effect is equivalent to the effective marginal tax rate for the high ability type derived by Pirtillä and Tuomala (1997) in a model with a competitive labor market. By rewriting the second row of equation (28) using $\partial \tilde{c}_{2}^{e} / \partial z=\partial c_{2}^{e} / \partial z-$ $\left[\left(\partial v^{e} / \partial z\right) /\left(\partial v^{e} / \partial B^{e}\right)\right]\left(\partial c_{2}^{e} / \partial B^{e}\right)$, we see that this term is also interpretable such that it contributes to increases the effective marginal tax rate, if $c_{2}^{e}$ is an overall normal good in the sense of being an increasing function of both $l$ and $B^{e}$.

An interesting observation from equation (28) is that $\mu / \gamma$ does not just appear as a separate term in the expression for the effective marginal tax rate; environmental aspects and employment effects interact. This is so because the aggregate demand for the dirty good depends on the employment. The latter has interesting implications for the commodity tax structure. By using equations (18), (19), (20) and (21), as well as the short notations,

$$
\frac{\partial \bar{c}_{1}}{\partial q_{k}}=n \frac{\partial \tilde{c}_{1}^{e}}{\partial q_{k}}+(m-n) \frac{\partial \tilde{c}_{1}^{u}}{\partial q_{k}}+\frac{\partial \tilde{c}_{1}^{p}}{\partial q_{k}}
$$




$$
\frac{\partial \bar{c}_{2}}{\partial q_{k}}=n \frac{\partial \tilde{c}_{2}^{e}}{\partial q_{k}}+(m-n) \frac{\partial \tilde{c}_{2}^{u}}{\partial q_{k}}+\frac{\partial \tilde{c}_{2}^{p}}{\partial q_{k}}
$$

for $k=1,2$, one can derive the result;

Proposition 4 Within the given framework, pareto efficient taxation means that the commodity tax structure satisfies

$$
\begin{gathered}
t_{1}=\frac{1}{\Delta}\left[\Phi_{1}(\Gamma, \mu / \gamma) \frac{\partial \bar{c}_{2}}{\partial q_{2}}-\Phi_{2}(\Gamma, \mu / \gamma) \frac{\partial \bar{c}_{2}}{\partial q_{1}}\right] \\
t_{2}=\frac{1}{\Delta}\left[\Phi_{2}(\Gamma, \mu / \gamma) \frac{\partial \bar{c}_{1}}{\partial q_{1}}-\Phi_{1}(\Gamma, \mu / \gamma) \frac{\partial \bar{c}_{1}}{\partial q_{2}}\right]+\frac{\mu}{\gamma} \frac{\partial \rho}{\partial C_{2}}
\end{gathered}
$$

where, for $j=1,2$,

$$
\begin{gathered}
\Phi_{j}(\Gamma, \mu / \gamma)=\left[-\Gamma+\frac{\mu}{\gamma} \frac{\partial \rho}{\partial C_{2}}\left(c_{2}^{e}-c_{2}^{u}\right)\right]\left[\frac{\partial n}{\partial q_{j}}+\frac{\partial n}{\partial B^{e}} c_{j}^{e}+\frac{\partial n}{\partial B^{u}} c_{j}^{u}\right] \text { and } \\
\Delta=\frac{\partial \bar{c}_{1}}{\partial q_{1}} \frac{\partial \bar{c}_{2}}{\partial q_{2}}-\frac{\partial \bar{c}_{1}}{\partial q_{2}} \frac{\partial \bar{c}_{2}}{\partial q_{1}}
\end{gathered}
$$

Proof: see the Appendix.

An interesting result in Proposition 4 is that the additivity property discussed in previous studies does not apply. This is seen from the functions $\Phi_{1}(\cdot)$ and $\Phi_{2}(\cdot)$, which are part of equations (30) and (31). Therefore, even if $(\mu / \gamma)\left(\partial \rho / \partial C_{2}\right)$ appears as a separate argument in the formula for the commodity tax on the dirty good and not in the corresponding formula for the clean good (as it would do in case the additivity property holds), $\mu / \gamma$ also interacts with the employment effects in the functions $\Phi_{1}(\cdot)$ and $\Phi_{2}(\cdot)^{13}$. To be able to provide the intuition behind equations (30) and (31) in the

\footnotetext{
${ }^{13}$ If the environmental damage is related to the production side of the economy, instead of to the consumption of a particular good as it is in this paper, similar aspect of emission taxation of firms may emerge.
} 
simplest possible way, I assume that the sum of changes in the compensated demand functions is such that $\Delta>0$, i.e. the determinant has the same properties as it would have if $\partial \bar{c}_{1} / \partial q_{k}$ and $\partial \bar{c}_{2} / \partial q_{k}$ for $k=1,2$, would refer to derivatives of the individual compensated demand functions.

Let me begin by considering how the employment effects of $t_{1}$ and $t_{2}$ interact with the 'compensated own price effects', $\partial \bar{c}_{1} / \partial q_{1}$ and $\partial \bar{c}_{2} / \partial q_{2}$, in equations (30) and (31). As can be seen, the interpretation of these parts of the tax formulas depends on whether the tax revenue motive to stimulate higher employment dominates the environmental motive of reducing the number of employed persons, or vice versa. If

$$
-\Gamma+\frac{\mu}{\gamma} \frac{\partial \rho}{\partial C_{2}}\left(c_{2}^{e}-c_{2}^{u}\right)=\Lambda
$$

is negative (positive), I will interpret this to mean that the tax revenue (environmental) motive is dominating. In addition, note that $\partial \bar{c}_{1} / \partial q_{1}<0$ and $\partial \bar{c}_{2} / \partial q_{2}<0$. Then, if $\partial n / \partial q_{j}<0$ for $j=1,2$, and if $\Lambda<0(>0)$, it follows that $\Lambda\left[\partial \bar{c}_{k} / \partial q_{k}\right]\left[\partial n / \partial q_{j}\right]<0(>0)$ for $j \neq k$. This implies that the employment effect of $t_{j}$ works to decrease (increase) the optimal $t_{j}$. The intuition is that a lower commodity tax stimulates the employment, which increases the welfare if $\Lambda<0$ and decreases the welfare if $\Lambda>0$. If, on the other hand, $\partial n / \partial q_{j}>0$ for $j=1,2$, these employment effects will influence the tax structure in exactly the opposite way.

In the absence of any cross price effects, the terms $\Lambda\left[\partial \bar{c}_{2} / \partial q_{2}\right]\left[\partial n / \partial q_{1}\right]$ and $\Lambda\left[\partial \bar{c}_{1} / \partial q_{1}\right]\left[\partial n / \partial q_{2}\right]$ would fully describe the qualitative influence that the employment effects of $t_{1}$ and $t_{2}$ have on the commodity tax structure. However, the influences that the consumer prices have on $n$ also affect equations (30) and (31) via the 'compensated cross price effects', $\partial \bar{c}_{1} / \partial q_{2}$ and $\partial \bar{c}_{2} / \partial q_{1}$. As such, they relate the employment effects of the commodity taxes to whether the dirty good is complementary with, or substitutable for, the clean good. To be able to provide an interpretation, I will concentrate on the 
situation where $\Lambda>0$. If $\partial n / \partial q_{2}>0$, and if the dirty good is complementary with (substitutable for) the clean good in the sense that $\partial \bar{c}_{2} / \partial q_{1}<0$ $(>0)$, there will be an incentive to increase (decrease) the commodity tax on the clean good in order to reduce the environmental damage. In this specific case, $t_{2}$ is not an 'ideal instrument' to control the aggregate demand for the dirty good, since an increase in $t_{2}$ increases $n$ and reduces $c_{2}^{i}$ for $i=e, u, p$. Therefore, if concern for the environment means that the optimal $t_{2}$ is relatively low, then the motive for using $t_{1}$ to reduce the demand for the dirty good by each agent type is stronger than it would otherwise have been. On the other hand, if $\partial n / \partial q_{2}<0$, the use of $t_{2}$ is no longer restricted from above via concern for the environment, which makes $t_{2}$ a more effective instrument for reducing the aggregate demand for the dirty good. As such, this also affects the use of $t_{1}$ : according to equation (30), the government uses less (more) of $t_{1}$ the more this tax reduces (increases) the tax base for the dirty good, ceteris paribus, which is a conventional efficiency aspect of commodity taxation. Finally, the interpretation corresponding to the situation where $\Lambda<0$ follows by analogy: the only difference is that the tax revenue motive to increase the number of employed persons determines the welfare contribution of the employment effects.

Turning to the remaining parts of the functions $\Phi_{1}(\cdot)$ and $\Phi_{2}(\cdot)$, note that $B^{e}$ and $B^{u}$ affect the commodity tax structure via

$$
\frac{\partial n}{\partial B^{e}} c_{j}^{e}+\frac{\partial n}{\partial B^{u}} c_{j}^{u} \text { for } j=1,2,
$$

These terms are interpretable in a similar way to a corresponding effect in equation (26), in which we found a relationship between the optimal levels of private income and environmental damage. In terms of equations (30) and (31), the basic intuition is that commodity taxation and private income constitute different means of affecting the utility of private consumption. Therefore, if consideration for employment tends to reduce the optimal pri- 
vate income, there is an incentive to adjust the commodity tax structure. This type of interaction between policy instruments has been addressed by Aronsson and Sjögren (2003) and will not be further discussed here.

\subsection{Briefly on Cost Efficient Environmental Policy}

Although I have touched upon environmental cost efficiency above, let me summarize it implications. By combining the calculations implicit in Propositions 1 and 2, we can derive;

Corollary 1 Within the given framework, the optimal uses of taxation and abatement obey

$$
\begin{aligned}
-\frac{1}{\partial \rho / \partial \alpha}= & \frac{1}{1-\nu}\left[n M W P_{x, B}^{e}+(m-n) M W P_{x, B}^{u}+M W P_{x, B}^{p}\right. \\
& -\Gamma\left(\frac{\partial n}{\partial x}+M W P_{x, B}^{e} \frac{\partial n}{\partial B^{e}}+M W P_{x, B}^{u} \frac{\partial n}{\partial B^{u}}\right) \\
& \left.-\sum_{j} t_{j}\left(n \frac{\partial \tilde{c}_{j}^{e}}{\partial x}+(m-n) \frac{\partial \tilde{c}_{j}^{u}}{\partial x}+\frac{\partial \tilde{c}_{j}^{p}}{\partial x}\right)\right]>0
\end{aligned}
$$

Corollary 1 means that the marginal cost in real terms of improving the environment via abatement, $-1 /(\partial \rho / \partial \alpha)$, is equal to the shadow price of environmental damage over the shadow price of the government's budget constraint. The latter represents the value for the government of reducing the environmental damage at the margin and is, therefore, also what governs the environmental aspects of the tax policy.

In the special case with full employment, $n=m$, and if the environmental damage is additively separable in terms of the utility function, it follows from equations (26), (30) and (31) that $\mu / \gamma=m M W P_{x, B}^{e}+M W P_{x, B}^{p}, t_{1}=0$ and $t_{2}=(\mu / \gamma)\left(\partial \rho / \partial C_{2}\right)$. Equation (32) can then be written to read

$$
-\frac{1}{\partial \rho / \partial \alpha}=t_{2} \frac{1}{\partial \rho / \partial C_{2}}
$$


In this case, there are two explicit environmental policy instruments, $t_{2}$ and $\alpha$, and the condition means that the marginal cost of reducing the environmental damage should be the same for the two instruments.

\section{Summary and Discussion}

In this paper, I consider environmental policy as part of a mixed tax problem, where the set of tax instruments contains a nonlinear income tax and linear commodity taxes. I assume that the environmental damage depends on the aggregate demand for one of the commodities, called a 'dirty' good. The labor market part of the model is a right-to-manage framework, where unions and firms bargain over the wage rate. The main purpose is to study how the interaction between the environmental damage and the labor market imperfection influences the public policy and, in particular, to analyze how it influences the use of commodity taxation when the public revenues can be raised by a general income tax.

The results show that the marginal social value of reduced environmental damage includes the sum of the marginal willingness to pay for reduced environmental damage among the consumers, a commodity tax revenue term and a feedback term as described in previous studies. However, in this paper, it also reflects how the number of employed persons will change in response to a reduction of the environmental damage. Furthermore, since different combinations of private income and environmental quality can be used to reach a given utility level, the social valuation of the environment will also be affected by the responsiveness of employment to changes in private income.

Since the equilibrium is characterized by unemployment, the optimal tax structure depends on how the use of each tax instrument affects the number of employed persons. Such employment effects influence the tax structure via two channels; (i) the tax revenues available for public expenditures de- 
pend on the employment, and (ii) the aggregate demand for the dirty good also depends on the employment. As a consequence, the use of taxation to counteract the labor market imperfection is not easily separated from the environmental aspects of tax policy. More specifically, the marginal social value of reduced environmental damage does not only give rise to an additional term in the tax formula for the dirty good (as it would do in case the labor market is competitive); it also interacts with the employment effects in the tax formulas for both the clean and the dirty good. This means that the so called 'additivity property' does not apply here.

The optimal tax structure depends on whether or not the 'tax revenue motive' to stimulate higher employment dominates the 'environmental motive' to reduce the number of employed persons. In addition, the compensated own price and cross price derivatives of demand that appear in the commodity tax formulas affect the interpretation of the employment effects mentioned above. As such, the precise use of commodity taxation in response to imperfect competition in the labor market and/or environmental damage also depends on whether the clean and dirty goods are complements or substitutes.

\section{Appendix}

\section{Proof of Proposition 3:}

As we saw in subsection 3.2, the effective marginal tax rate for an employed individual can in its basic form be written as

$$
\tau_{y}=T_{y}+\sum_{j} t_{j}\left[\frac{\partial c_{j}^{e}}{\partial B^{e}}\left(1-T_{y}\right)-\frac{1}{w} \frac{\partial c_{j}^{e}}{\partial z}\right]
$$

By using equation (3) to define $T_{y}=-\left(\partial v^{e} / \partial z\right) /\left(\partial v^{e} / \partial B^{e}\right)+1$, we can rewrite equation $(\mathrm{A} 1)$ as 


$$
\tau_{y}=1+\frac{1}{w} \sum_{j} Q_{j} \frac{\partial c_{j}^{e}}{\partial z}-\frac{1}{w}\left[\frac{\partial v^{e}}{\partial z} / \frac{\partial v^{e}}{\partial B^{e}}\right] \sum_{j} Q_{j} \frac{\partial c_{j}^{e}}{\partial B^{e}}
$$

Let us multiply the quotient $\left(\partial v^{e} / \partial z\right) /\left(\partial v^{e} / \partial B^{e}\right)$ by the right hand side of equation (18). By using equation (17), one can then derive

$$
\begin{aligned}
-\left[\frac{\partial v^{e}}{\partial z} / \frac{\partial v^{e}}{\partial B^{e}}\right] \sum_{j} Q_{j} \frac{\partial c_{j}^{e}}{\partial B^{e}}= & \frac{1}{n}\left[-\Gamma \frac{\partial n}{\partial l}+\frac{\mu}{\gamma} \frac{\partial \rho}{\partial C_{2}} \frac{\partial C_{2}}{\partial l}\right]-w \\
& +\frac{1}{n}\left[\frac{\partial v^{e}}{\partial z} / \frac{\partial v^{e}}{\partial B^{e}}\right]\left[-\Gamma \frac{\partial n}{\partial B^{e}}+\frac{\mu}{\gamma} \frac{\partial \rho}{\partial C_{2}} \frac{\partial C_{2}}{\partial B^{e}}\right]
\end{aligned}
$$

Finally, by substituting equation (A3) into equation (A2) and using

$$
\begin{gathered}
\frac{\partial C_{2}}{\partial l}=\frac{\partial n}{\partial l}\left[c_{2}^{e}-c_{2}^{u}\right]-n \frac{\partial c_{2}^{e}}{\partial z} \\
\frac{\partial C_{2}}{\partial B^{e}}=\frac{\partial n}{\partial B^{e}}\left[c_{2}^{e}-c_{2}^{u}\right]+n \frac{\partial c_{2}^{e}}{\partial B^{e}} \\
\frac{\partial c_{2}^{e}}{\partial z}=\frac{\partial \tilde{c}_{2}^{e}}{\partial z}+\frac{\partial c_{2}^{e}}{\partial B^{e}}\left[\frac{\partial v^{e}}{\partial z} / \frac{\partial v^{e}}{\partial B^{e}}\right]
\end{gathered}
$$

we obtain equation (28).

Equation (29):

To show that

$$
\frac{\partial n}{\partial l}+\left[\frac{\partial v^{e}}{\partial z} / \frac{\partial v^{e}}{\partial B^{e}}\right] \frac{\partial n}{\partial B^{e}}
$$

is negative if $\partial^{2} v^{e} / \partial z \partial B^{e} \geq 0$, observe that

$$
\frac{\partial n}{\partial l}=\frac{\partial \hat{n}}{\partial l}+\frac{\partial \hat{n}}{\partial w} \frac{\partial w}{\partial l}
$$

and

$$
\frac{\partial n}{\partial B^{e}}=\frac{\partial \hat{n}}{\partial w} \frac{\partial w}{\partial B^{e}}
$$


where $\left(\partial v^{e} / \partial z\right) /\left(\partial v^{e} / \partial B^{e}\right)>0, \partial \hat{n} / \partial l<0, \partial \hat{n} / \partial w<0$ and $\partial w / \partial l>0$. By using equation (9), we can derive

$$
\begin{gathered}
\frac{\partial w}{\partial l}=-\frac{\left[a U_{w l} \pi+(1-a) \Phi_{l} \pi_{w}\right]}{\Phi^{1-a} \pi^{a} \tilde{\Omega}_{w w}} \\
\frac{\partial w}{\partial B^{e}}=-\frac{\left[a U_{w c^{e}} \pi+(1-\alpha) \Phi_{B^{e}} \pi_{w}\right]}{\Phi^{1-a} \pi^{a} \tilde{\Omega}_{w w}}
\end{gathered}
$$

in which

$$
\begin{gathered}
U_{w l}=-\frac{\partial L}{\partial w} \frac{1}{l^{2} m}\left[v^{e}-v^{u}\right]-\frac{\partial L}{\partial w} \frac{1}{l m} \frac{\partial v^{e}}{\partial z}-\frac{L}{m w} \frac{\partial^{2} v^{e}}{\partial z^{2}} \\
U_{w B^{e}}=\frac{\partial L}{\partial w} \frac{1}{l m} \frac{\partial v^{e}}{\partial B^{e}}+\frac{L}{m w} \frac{\partial^{2} v^{e}}{\partial z \partial B^{e}} \\
\Phi_{l}=-\frac{L}{l^{2} m}\left[v^{e}-v^{u}\right]-\frac{L}{l m} \frac{\partial v^{e}}{\partial z} \\
\Phi_{B^{e}}=\frac{L}{l m} \frac{\partial v^{e}}{\partial B^{e}}
\end{gathered}
$$

By substituting equations (A5), (A6), (A7) and (A8) into equation (A4), we obtain the result mentioned above.

Proof of Proposition 4:

Note first that $\partial v^{i} / \partial q_{k}$ in equations (21) can be replaced by $-\left(\partial v^{i} / \partial B^{i}\right) x_{k}^{i}$ for $i=e, u, p$ and $k=1,2$, by using Roy's identity. Then, by using equations (18), (19), (20) and (21) together with

$$
\begin{gathered}
\sum_{j} Q_{j} \frac{\partial c_{j}^{i}}{\partial q_{k}}=-c_{k}^{i}-\sum_{j} t_{j} \frac{\partial c_{j}^{i}}{\partial q_{k}} \\
\frac{\partial \tilde{c}_{j}^{i}}{\partial q_{k}}=\frac{\partial c_{j}^{i}}{\partial q_{k}}+\frac{\partial c_{j}^{i}}{\partial B^{i}} x_{k}^{i}
\end{gathered}
$$


we can define the following equation system;

$$
\begin{aligned}
& \sum_{j} t_{j}\left[n \frac{\partial \tilde{c}_{j}^{e}}{\partial q_{1}}+(m-n) \frac{\partial \tilde{c}_{j}^{u}}{\partial q_{1}}+\frac{\partial \tilde{c}_{j}^{p}}{\partial q_{1}}\right] \\
= & -\Gamma\left[\frac{\partial n}{\partial q_{1}}+\frac{\partial n}{\partial B^{e}} c_{1}^{e}+\frac{\partial n}{\partial B^{u}} c_{1}^{u}\right]+\frac{\mu}{\gamma} \frac{\partial \rho}{\partial C_{2}}\left[\frac{\partial C_{2}}{\partial q_{1}}+\frac{\partial C_{2}}{\partial B^{e}} c_{1}^{e}+\frac{\partial C_{2}}{\partial B^{u}} c_{1}^{u}+\frac{\partial C_{2}}{\partial B^{p}} c_{1}^{p}\right] \\
& \sum_{j} t_{j}\left[n \frac{\partial \tilde{c}_{j}^{e}}{\partial q_{2}}+(m-n) \frac{\partial \tilde{c}_{j}^{u}}{\partial q_{2}}+\frac{\partial \tilde{c}_{j}^{p}}{\partial q_{2}}\right] \\
= & -\Gamma\left[\frac{\partial n}{\partial q_{2}}+\frac{\partial n}{\partial B^{e}} c_{2}^{e}+\frac{\partial n}{\partial B^{u}} c_{2}^{u}\right]+\frac{\mu}{\gamma} \frac{\partial \rho}{\partial C_{2}}\left[\frac{\partial C_{2}}{\partial q_{2}}+\frac{\partial C_{2}}{\partial B^{e}} c_{2}^{e}+\frac{\partial C_{2}}{\partial B^{u}} c_{2}^{u}+\frac{\partial C_{2}}{\partial B^{p}} c_{2}^{p}\right]
\end{aligned}
$$

By using

$$
\begin{gathered}
\frac{\partial C_{2}}{\partial q_{k}}=\frac{\partial n}{\partial q_{k}}\left[c_{2}^{e}-c_{2}^{u}\right]+n \frac{\partial c_{2}^{e}}{\partial q_{k}}+(m-n) \frac{\partial c_{2}^{u}}{\partial q_{k}}+\frac{\partial c_{2}^{p}}{\partial q_{k}} \text { for } k=1,2 \\
\frac{\partial C_{2}}{\partial B^{e}}=\frac{\partial n}{\partial B^{e}}\left[c_{2}^{e}-c_{2}^{u}\right]+n \frac{\partial c_{2}^{e}}{\partial B^{e}} \\
\frac{\partial C_{2}}{\partial B^{u}}=\frac{\partial n}{\partial B^{u}}\left[c_{2}^{e}-c_{2}^{u}\right]+(m-n) \frac{\partial c_{2}^{u}}{\partial B^{u}} \\
\frac{\partial C_{2}}{\partial B^{p}}=\frac{\partial c_{2}^{p}}{\partial B^{p}} \\
\frac{\partial c_{j}^{i}}{\partial q_{k}}=\frac{\partial \tilde{c}_{j}^{i}}{\partial q_{k}}-\frac{\partial c_{j}^{i}}{\partial B^{i}} c_{k}^{i} \text { for } i=e, u, p, j=1,2 \text { and } k=1,2
\end{gathered}
$$

we can rewrite equations (A11) and (A12) to read

$$
\left[\begin{array}{cc}
\frac{\partial \bar{c}_{1}}{\partial q_{1}} & \frac{\partial \bar{c}_{2}}{\partial q_{1}} \\
\frac{\partial \bar{c}_{1}}{\partial q_{2}} & \frac{\partial \bar{c}_{2}}{\partial q_{2}}
\end{array}\right]\left[\begin{array}{c}
t_{1} \\
t_{2}
\end{array}\right]=\left[\begin{array}{l}
\Phi_{1}(\Gamma, \mu / \gamma)+\frac{\mu}{\gamma} \frac{\partial \rho}{\partial C_{2}} \frac{\partial \bar{c}_{2}}{\partial q_{1}} \\
\Phi_{2}(\Gamma, \mu / \gamma)+\frac{\mu}{\gamma} \frac{\partial \rho}{\partial C_{2}} \frac{\partial \bar{c}_{2}}{\partial q_{2}}
\end{array}\right]
$$

where the functions $\Phi_{1}(\Gamma, \mu / \gamma)$ and $\Phi_{2}(\Gamma, \mu / \gamma)$ as well as $\partial \bar{c}_{j} / \partial q_{k}$ for $j=1,2$, and $k=1,2$, were defined in the text. By solving equations (A18), we obtain equations (30) and (31). 


\section{References}

[1]Aronsson, T. and Blomquist, S. (2003). Optimal Taxation, Global Externalities and Labor Mobility. Forthcoming in The Journal of Public Economics.

[2]Aronsson, T. and Sjögren, T. (2002a) Is the Optimal Labor Income Tax Progressive in a Unionized Economy? Umea Economic Studies no 587.

[3]Aronsson, T. and Sjögren, T. (2002b) Efficient Taxation, Wage Bargaining and Policy Coordination. Umea Economic Studies no 601.

[4]Aronsson, T. and Sjögren, T. (2003) Income Taxation, Commodity Taxation and Provision of Public Goods under Labor Market Distortions. Forthcoming in FinanzArchiv.

[5]Atkinson, A.B. and Stiglitz, J.E. (1976) The design of tax structure: direct versus indirect taxation. Journal of Public Economics 1, 55-75.

[6]Boadway, R. and Marceau, N. (1994) Minimum Wage Legislation and Unemployment Insurance as Instruments for Redistribution. The Scandinavian Journal of Economics 96, 67-81.

[7]Bovenberg, L. and van der Ploeg, F. (1996) Optimal Taxation, Public Goods and Environmental Policy with Involuntary Unemployment. Journal of Public Economics 62, 69-83.

[8]Bovenberg, L. and van der Ploeg, F. (1998) Tax Reform, Structural Unemployment and the Environment. The Scandinavian Journal of Economics 100, 593-610.

[9]Christiansen, V. (1981) Evaluation of Projects under Optimal Taxation. Review of Economic Studies 48, 447-457. 
[10]Christiansen, V. (1984) Which Commodity Taxes should Supplement the Income Tax? Journal of Public Economics 24, 195-220.

[11]Cremer, H. and Gahvari, F. (2001) Second-Best Taxation of Emission and Polluting Goods. Journal of Public Economics 80, 169-197.

[12]Cremer, H., Gahvari, F. and Ladoux, N. (2001) Second-Best Pollution Taxes and the Structure of Preferences. Southern Economic Journal 68, $258-280$.

[13]Edwards, J., Keen, M. and Tuomala, M. (1994) Income Tax, Commodity Tax and Public Good Provision. Finanzarchiv 51, 472-497.

[14]Koskela, E. and Schöb, R. (1999) Alleviating Unemployment: The Case for Green Tax Reforms. European Economic Review 43, 1723-1746.

[15]Koskela, E, Schöb, R. and Sinn, H-W. (2001) Green Tax Reform and Competitiveness. German Economic Review 2, 19-30.

[16]Mirrlees, J., A. (1976) Optimal Tax Theory: A Synthesis. Journal of Public Economics 6, 327-358.

[17]Oswald, A.J. (1985) The Economic Theory of Trade Unions: An Introductory Survey. The Scandinavian Journal of Economics 87, 160-193.

[18]Pirttilä, M. and Tuomala, M. (1997) Income Tax, Commodity Tax and Environmental Policy. International Tax and Public Finance 3, 379-393.

[19]Schneider, K. (1997) Involuntary Unemployment and Environmental Policy: The Double Dividend Hypothesis. The Scandinavian Journal of Economics 99, 45-59.

[20]Stern, N.H. (1982) Optimum Taxation with Errors in Administration. Journal of Public Economics 17, 181-211. 
[21]Stiglitz, J.E. (1982) Self-Selection and Pareto Efficient Taxation. Journal of Public Economics 17, 213-240. 